\title{
Evaluation of Marshall Compactor Effect on the Degradation of Recycled Concrete Aggregate
}

\author{
Gailan Ismat Safa Eldeen ${ }^{1,2}$, Fauzan Mohd Jakarni ${ }^{1}$, Ratnasamy Muniandy ${ }^{1}$, Salihudin Hassim ${ }^{1}$ \\ ${ }^{1}$ Department of Civil Engineering, Faculty of Engineering, University Putra Malaysia, Serdang, Malaysia \\ ${ }^{2}$ Deartment of Civil Techniques, Northern University, Kirkuk Technical Institute, Kirkuk, Iraq
}

Email address:

gailan2004@yahoo.com (G. I. S. Eldeen), fauzan.mj@upm.edu.my (F. M. Jakarni)

\section{To cite this article:}

Gailan Ismat Safa Eldeen, Fauzan Mohd Jakarni, Ratnasamy Muniandy, Salihudin Hassim. Evaluation of Marshall Compactor Effect on the Degradation of Recycled Concrete Aggregate. Journal of Civil, Construction and Environmental Engineering.

Vol. 3, No. 5, 2018, pp. 133-146. doi: 10.11648/j.jccee.20180305.11

Received: October 17, 2018; Accepted: November 14, 2018; Published: December DD, 2018

\begin{abstract}
Demolishing structures presents the problem of disposing of crushed cement and concrete. This form of pollution is a cause for anxiety for environmental awareness agencies, inspiring the creation of more construction and structural policies and regulations that aim to address handling and disposing of crushed concrete. In place of throwing away crushed concrete, it ought to be reused. This study explores the feasibility of reusing crushed concrete in pavement construction applications, by adding it as substitute for aggregate in asphalt mixtures. The study focuses on the physical properties of crushed concrete and its degradation after the compaction of aggregates; in particular, it takes into account its absorption and abrasion qualities. The generally accepted advice is to mix crushed concrete with naturally sourced conventional aggregates. This study evaluated the suitability of variously proportioned and graded mixtures of conventional aggregates and Recycled Concrete Aggregate (RCA); six different proportions $(0 \%, 20 \%, 40 \%, 60 \%, 80 \%$ and $100 \%)$ and five grades of crushed cement concrete were assessed using a $5 \mathrm{~mm}$ aggregate passing sieve and a $1.18 \mathrm{~mm}$ retaining sieve. The resulting mixtures were subjected to compaction of $20,40,60,80$ or 100 blows, using a Marshall Compactor. The results of the study reveal that the crushed concrete and the mixtures with the recommended ranges of sieve sizes and conventional aggregates are suitable for roads that have a medium volume of traffic.
\end{abstract}

Keywords: Recycled Concrete Aggregate, Asphalt Mixtures, Compaction, Recycling, Aggregate Gradation, Degradation, Environment

\section{Introduction}

Demolishing old concrete structures, results in recycled concrete aggregate (RCA). As a consequence of war, earthquakes and destruction, there has been an increasing in the number of old structures being rebuilt. Over the years, demolition waste has contaminated soil and water, and influenced climate change [1]. The situation has been compounded by recent increases in price of land, leading to high dumping costs at landfill sites. Contractors have observed that nowadays, the costs of demolition exceed those of recycling [2]. For every kilometre of flexible pavement, around 12,500 tons of natural aggregates are required [3]. Therefore, highway construction projects are the largest consumers of aggregates, affecting the overall amount of natural aggregates available [4]. Using RCA offers the significant advantages of reducing the need for natural aggregates and promoting environmental considerations.

As the specifications for lower layers are not as rigorous as those for upper layers are, early research focused on using RCA as a granular material in base and sub-base layers [5]. It was only later that it was realised that RCA is readily soluble in water, increasing the $\mathrm{pH}$ of groundwater and affecting the vegetation close to the road [6]; hot mix and asphalt-coated layers do not have the same effect.

The use of RCA in hot-mix asphalt (HMA) has been the subject of recent research. Results from these studies indicate that the properties of RCA are determined by the mortar connected to the RCA surface, and these properties diverge from those of natural aggregate [7]. Mortar confers RCA with low specific gravity and lower density enabling the RCA mixture to be transferred to the asphalt mixture $[8,9]$. 
Compared to natural aggregate, the connected mortar gives the RCA greater porosity, enabling RCA to absorb more asphalt from the mixture [5]. As a result, the asphalt content of the mixture is optimised [10]. The optimal asphalt content is contingent upon RCA particle size [11], as smaller particles have a larger surface area-to-volume ratio [12].

RCAs also differ to natural aggregate in relation to its abrasion value. RCA is unable to satisfy the requirements of abrasion, due to its higher abrasion value [13]. After compaction, aggregate that has a high abrasion as determined by a Los Angeles Abrasion test, is vulnerable to greater degradation than other types of aggregates [14]. It is anticipated that RCA will have a high value of abrasion after compaction; thus, it is important to study this aspect to determine RCA degradation. In this study defines degradation as being 'the breakdown of aggregate via mechanical action'. The result of aggregate particles breaking down includes air voids in the mix (VTM) and a loss of voids in the mineral aggregate (VMA) [15]. Both VTM and VMA can impact the durability of the mixture [16]. Furthermore, as a consequence of breakdown, the binder film around the aggregate breaks, enabling water to enter the mix and causing moisture damage of moisture to the pavement [17]. There are two means by which aggregate breakdown can occur, 1) the aggregate wears away, with small pieces breaking off; and 2) the aggregate fractures. Wearing is a product of the aggregate's angularity and abrasion value; fractures occur applied stress exceeds the strength of the aggregate [18].

The factors that influence aggregate degradation most are aggregate gradation and energy of compaction [18]. The breakdown of aggregate is prevented by suitable gradation. According to the Marshall hammer exhibition, aggregate breaks down more other compactors [17]. The size of aggregate is a vital factor in boosting degradation, with larger particle sizes leading to higher degradation values. Denser gradation is associated with reduced degradation. The shape of aggregate particles also influences degradation, with flat and elongated particles being associated with increased occurrence of fractures and breakdown [19]. The extent of degradation can be minimised by controlling by the grade of aggregate selected [20].

The objectives of this study are:

1) To compare the degradation between natural aggregate and RCA;

2) To evaluate the effect of aggregate gradation on degradation and select the energy of compaction that generates less degradation.

The degradation of aggregate was determined without adding asphalt to the mixture. Six different proportions and five different grades of RCA were evaluated. All samples were placed on a Marshall Compaction pedestal and were subjected to 20, 40, 60, 80 and 100 blows.

\section{Materials and Methods}

The study evaluated RCA and natural aggregate. RCA was obtained from various concrete demolition waste, while the natural aggregate was granite, obtained from Kajang Rocks Quarry. To ensure their appropriateness, the properties of the RCA and natural aggregate were established (Table 1).

Table 1. The Mechanical and Physical Properties of Aggregate.

\begin{tabular}{|c|c|c|c|}
\hline \multirow{3}{*}{$\begin{array}{l}\text { Aggregate size } \\
(\mathrm{mm}) \\
\text { passing-retained }\end{array}$} & \multicolumn{2}{|l|}{ Test } & \multirow{3}{*}{$\begin{array}{l}\text { Specification } \\
\text { ASTM C131 [21] }\end{array}$} \\
\hline & \multicolumn{2}{|c|}{ Los Angeles Abrasion value } & \\
\hline & Granite & RCA & \\
\hline $19-9.5$ & 20 & 35 & \\
\hline $9.5-4.75$ & 20 & 36 & $30 \max$ \\
\hline $4.75-2.36$ & 19 & 28 & \\
\hline Test & \multicolumn{2}{|c|}{ Bulk specific gravity } & \multirow[t]{7}{*}{ ASTM C127 [22] } \\
\hline $20-14$ & 2.5 & 2.22 & \\
\hline $.14-10$ & 2.55 & 2.32 & \\
\hline $.10-5$ & 2.601 & 2.38 & \\
\hline $5-3.35$ & 2.618 & 2.36 & \\
\hline $3.35-1.18$ & 2.621 & 2.285 & \\
\hline $1.18-0.075$ & 2.66 & 2.37 & \\
\hline Test & \multicolumn{2}{|l|}{ Absorption } & $\begin{array}{l}\text { ASTM C127 [22], } \\
\text { ASTM C128 [23] }\end{array}$ \\
\hline $20-14$ & 0.6 & 4 & \\
\hline $.14-10$ & 0.5 & 6 & \multirow{5}{*}{$2 \% \max$} \\
\hline $.10-5$ & 0.8 & 7 & \\
\hline $5-3.35$ & 0.9 & 10 & \\
\hline $3.35-1.18$ & 0.7 & 12 & \\
\hline $1.18-0.075$ & 1.2 & 18 & \\
\hline Test & \multicolumn{2}{|c|}{$\begin{array}{l}\text { Flakiness Index and Elongation } \\
\text { Index }\end{array}$} & BS 812: Part 3 \\
\hline Flakiness Index & 18.1 & 16 & $20 \max$ \\
\hline \multirow[t]{2}{*}{ Elongation Index } & 7 & 5 & $20 \max$ \\
\hline & \multicolumn{2}{|c|}{ Soundness Test } & ASTM C88 \\
\hline $19-9.5$ & 2.14 & 3.7 & \\
\hline $9.5-4.75$ & 2.3 & 3.9 & \\
\hline $4.75-2.36$ & 2.43 & 4.1 & \\
\hline \multirow[t]{3}{*}{$2.36-1.18$} & 2.55 & 4.36 & \\
\hline & 9.42 & 16.06 & \\
\hline & \multicolumn{2}{|l|}{ Impact test } & \multirow{6}{*}{$\begin{array}{l}\text { BS 812: Part III } \\
\text { 15\% Max } \\
\text { MS } 7.5\end{array}$} \\
\hline Impact test & 11 & 26 & \\
\hline & \multicolumn{2}{|c|}{ Angularity number } & \\
\hline $19-12.5$ & 5.3 & 7.1 & \\
\hline $12.5-9.5$ & 6.4 & 11.6 & \\
\hline \multirow[t]{2}{*}{$9.5-4.75$} & 9.3 & 15.8 & \\
\hline & \multicolumn{2}{|c|}{ Particle Shape Index } & \multirow[t]{4}{*}{ ASTM D3398[24] } \\
\hline $19-12.5$ & 11 & 15 & \\
\hline $12.5-9.5$ & 11 & 19 & \\
\hline $9.5-4.75$ & 14 & 18 & \\
\hline
\end{tabular}

The results show that the specific gravity of RCA is lower than that of granite; specific gravity increases inversely to particle size. The Los Angeles RCA and granite abrasion value were also evaluated. The abrasion of value of RCA was found to be higher than granite's, and this value fell in line with reduced RCA particle size. The aggregate gradations of all mixtures used in this study followed the technical recommendations of the Malaysian Standard Specification for Road Works (JKR). Due to its appropriateness for light and medium traffic volumes, hot-mix asphalt (HMA14) gradation was used. Figure 1 and Table 2 detail the aggregate gradations used. Table 3 presents the percentage of fine and coarse aggregate used in each gradation. To achieve adequate gradation, five gradations were used (representing lower aggregate degradation value). 




Figure 1. Aggregate Particle Size Distribution.

Table 2. Used Aggregate Gradations.

\begin{tabular}{llllll}
\hline Aggregate size (mm) & $\begin{array}{l}\text { Lower limit G1 } \\
\text { Percent Passing }\end{array}$ & $\begin{array}{l}\text { Upper limit G2 } \\
\text { Percent Passing }\end{array}$ & $\begin{array}{l}\text { Median G3 } \\
\text { Percent Passing }\end{array}$ & $\begin{array}{l}\text { G4 } \\
\text { Percent Passing }\end{array}$ & $\begin{array}{l}\text { G5 } \\
\text { Percent Passing }\end{array}$ \\
\hline 20 & 100 & 100 & 100 & 100 & 100 \\
14 & 90 & 100 & 95 & 100 & 90 \\
10 & 76 & 86 & 81 & 85.4 & 77 \\
5 & 50 & 62 & 56 & 60.3 & 52 \\
3.35 & 40 & 54 & 47 & 52 & 43 \\
1.18 & 18 & 26 & 31.1 & 21 \\
0.425 & 12 & 18 & 20.7 & 16 \\
0.15 & 6 & 14 & 10 & 10.3 & 10 \\
0.075 & 4 & 6 & 4 & \\
\hline
\end{tabular}

Table 3. Percent of Coarse and Fine Aggregate in Each Gradation.

\begin{tabular}{llllll}
\hline & G1 & G2 & G3 & G4 & G5 \\
\hline Coarse $\%$ & 50 & 38 & 44 & 40 & 48 \\
Fine $\%$ & 46 & 54 & 50 & 56 & 44 \\
Filler $\%$ & 4 & 8 & 6 & 4 & 8 \\
\hline
\end{tabular}

The RCA used has a passing sieve size of $5 \mathrm{~mm}$ and a retaining sieve size of $1.18 \mathrm{~mm}$. These criteria were selected because larger-sized aggregate has a higher abrasion value and less specific gravity. Furthermore, the absorption value of aggregate passing sieve size of $1.18 \mathrm{~mm}$ is high. Different percentages of RCA were blended with granite $(0 \%, 20 \%$, $40 \%, 60 \%, 80 \%$ and $100 \%$ ).

Samples weighing 1200 gm were prepared in accordance with the Malaysian Standard Specification for Road Works JKR specification. Each sample was mixed to prevent segregation then placed in a Marshall mould, with a 101.6 $\mathrm{mm}$ diameter. Using a new tamping rod purposely manufactured for this study, the mix was then tamped with 30 blows to reach maximum density. The mould was then placed on a Marshal Compaction pedestal and was given 20, 40, 60, 80 and 100 blows. The mix was sieved in the same set of the sieves and the weight of retained aggregate on each sieve was measured.
Changes in passing percentage for each fraction and all groups were determined. Equation 1 was used to determine the values:

$$
C P P=\frac{(P b-P a)}{p b} * 100
$$

Where CPP is the change in passing percentage, $\mathrm{Pb}$ is the passing percentage before compaction and $\mathrm{Pa}$ is the passing percentage after compactions.

As Figure 2 depicts, the tamping rod was made from steel and consists of two cylindrical parts. The length of the small part is $40 \mathrm{~mm}$ and the diameter is $45 \mathrm{~mm}$. The larger part measures $300 \mathrm{~mm}$ length and $16 \mathrm{~mm}$ diameter. The diameter of $45 \mathrm{~mm}$ was selected because it approximately half of the Marshall Mould diameter. The tamping rod weighed 957.9 gm. The rod is inside a hollow cylinder, which has an internal diameter of $50 \mathrm{~mm}$ and $280 \mathrm{~mm}$ length. One end of the hollow cylinder was open; the other had a perforated cap. The cap had a central hole through which the tamping rod was passed through. Other small holes in the cap allowed the air to enter the cylinder while the rod was tamped. Five small holes on the bottom surface of the hollow cylinder enabled air to escape while the tamping rod was dropped. 



Figure 2. Dimension of Tamping Rod.

The aggregate was placed in the Marshall mould then, the tamping rod was placed on the mixture and was allowed to drop freely around the perimeter of the aggregate $5,10,15$, $20,25,30$ and 35 times. Then by rolling the rod on the mould as shown in Figure 3, the surface was levelled. The weight of the aggregate was measured after each attempt. The air voids were calculated using Equation [24]. From this, the optimal number of blows required for the mixture to reach maximum density was determined.

$$
\mathrm{Va}=[1-(\mathrm{M} / \mathrm{SV})]^{*} 100
$$

Where:

$\mathrm{Va}=$ voids in aggregate

$\mathrm{M}=$ average mass of the aggregate in the mould (g)

$\mathrm{S}=$ bulk specific gravity of the aggregate

$\mathrm{V}=$ volume of the cylindrical mould $(\mathrm{ml})$

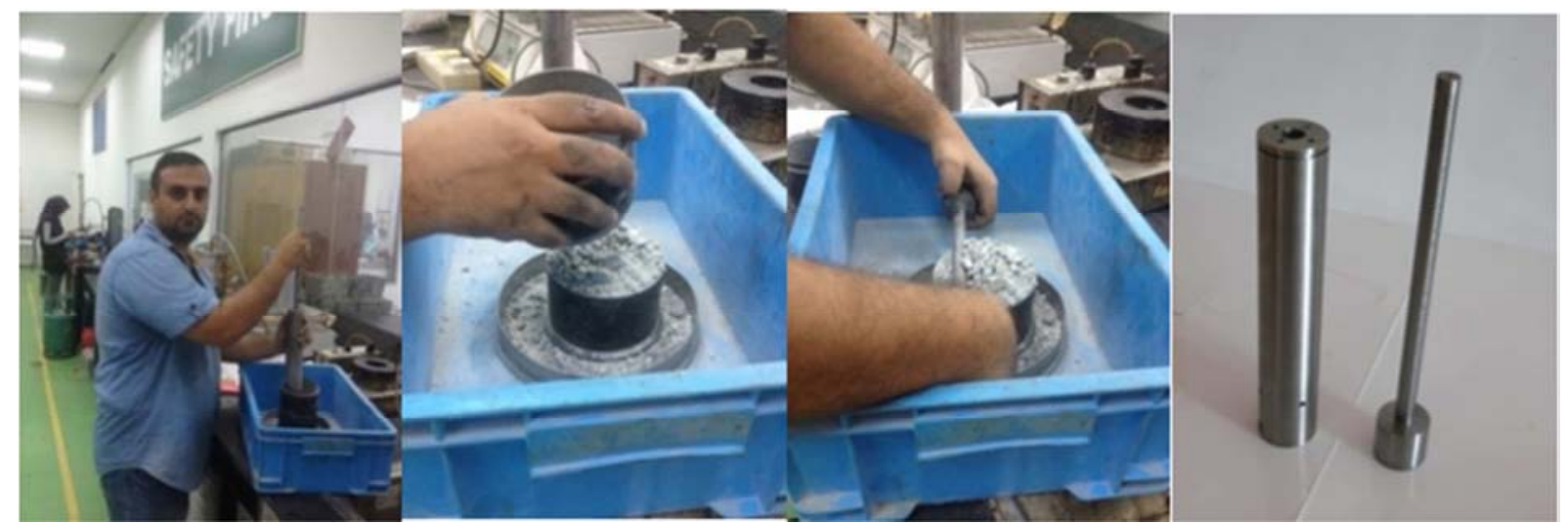

Figure 3. Number of Blows Determination.

\section{Results}

\subsection{Passing Percentages after Compaction}

In order to compare aggregate gradations and RCA percentages on aggregate degradation, the passing percentages for each sieve after compaction were calculated. The aggregate particle size distributions after compaction for all groups and HMA gradation limitations (upper and lower limit) are drawn in Figures 4 to 9. It can be observed that gradations G1, G3 and G5 after compaction were within the requirement limitations. Whereas, G2 and G4 were outside the upper limitation. This is because G1 represents the lower limitation, G5 is close to the lower limitation and G3 is the median gradation, therefore an increase in passing percentage for these gradations is still far from the upper boundary. 
Conversely, G2 represents the upper limitation and G4 is close to the upper limitation, therefore an increase in passing percentage for these gradations can be above the upper

G1

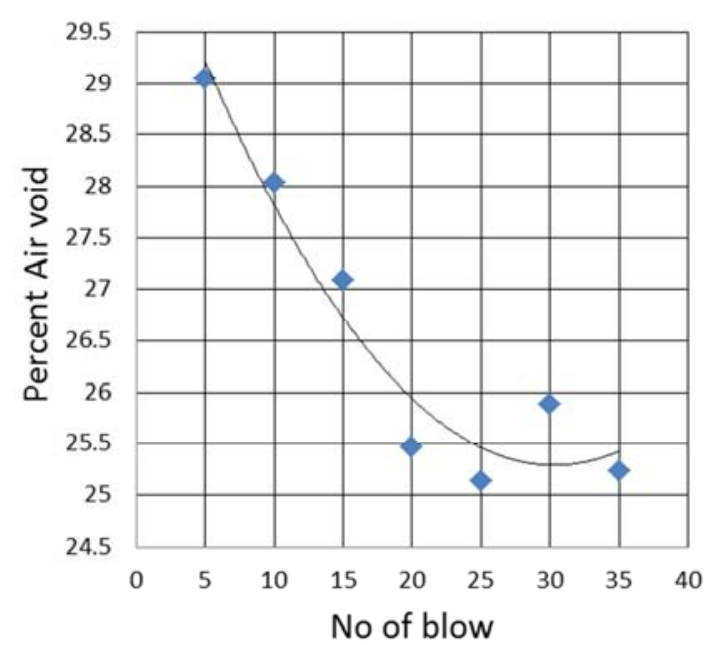

G3

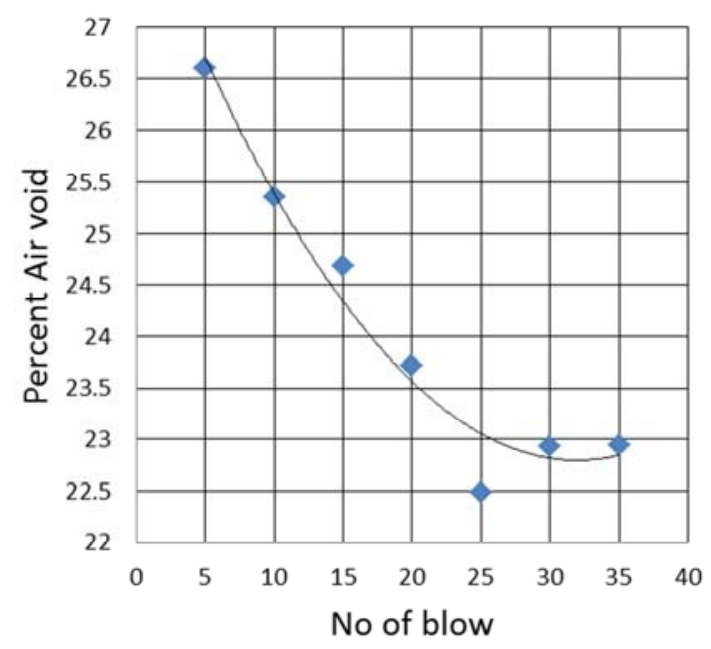

G5

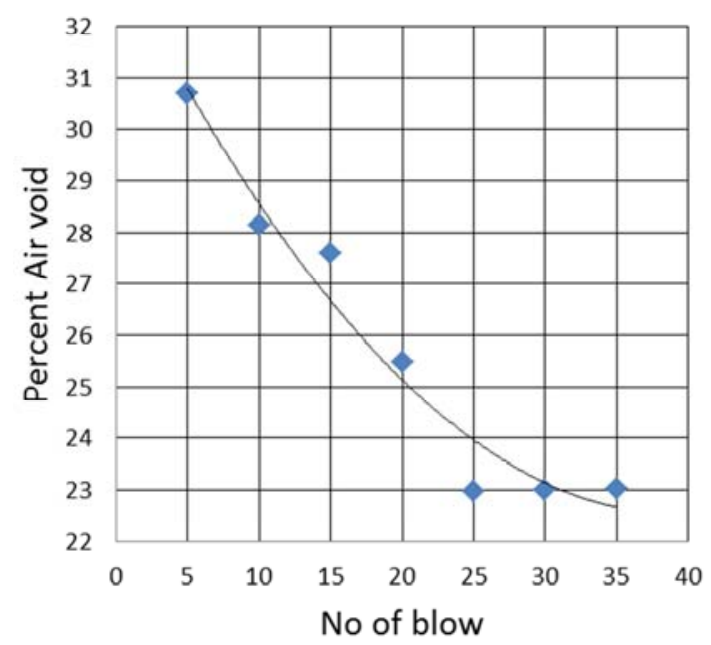

boundary. Moreover, degradation occurs for both the granite aggregate and RCA, therefore it is important to evaluate each fraction separately.

G2

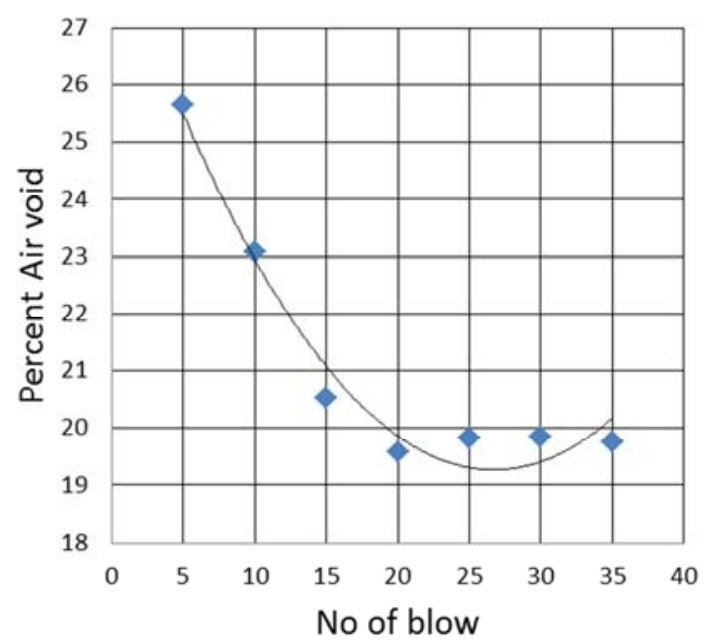

G4

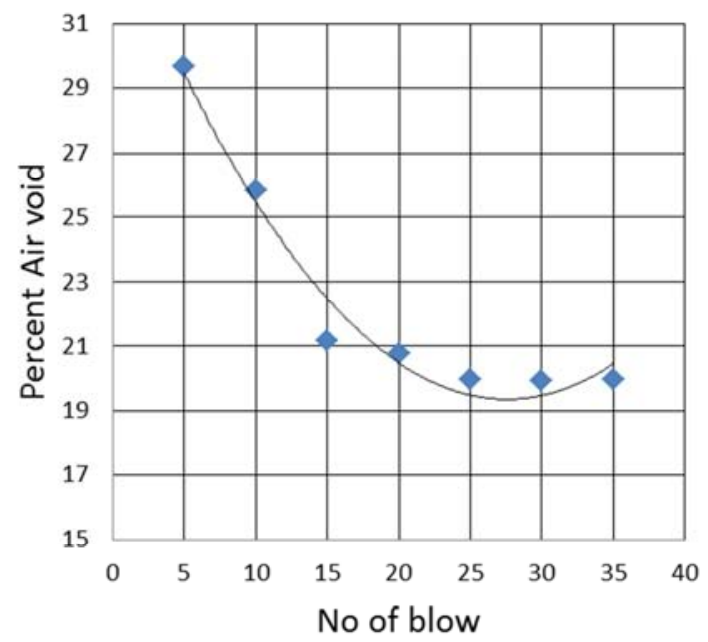

Figure 4. Number of Blow Determination for Granite. 


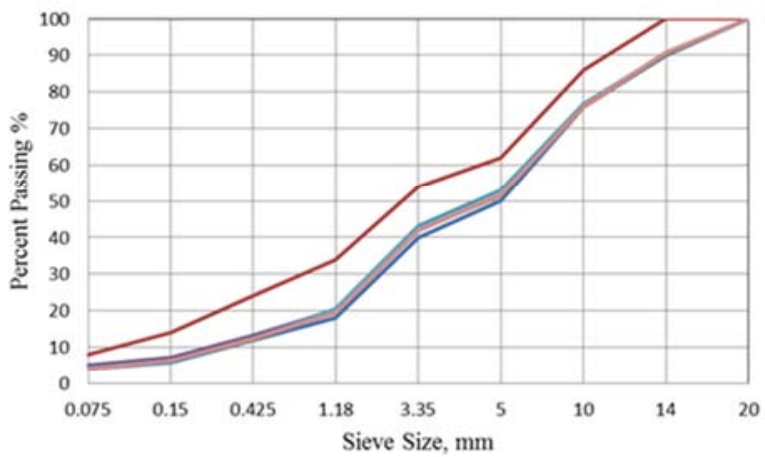

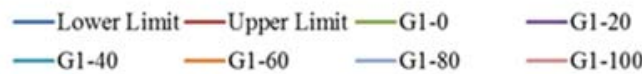

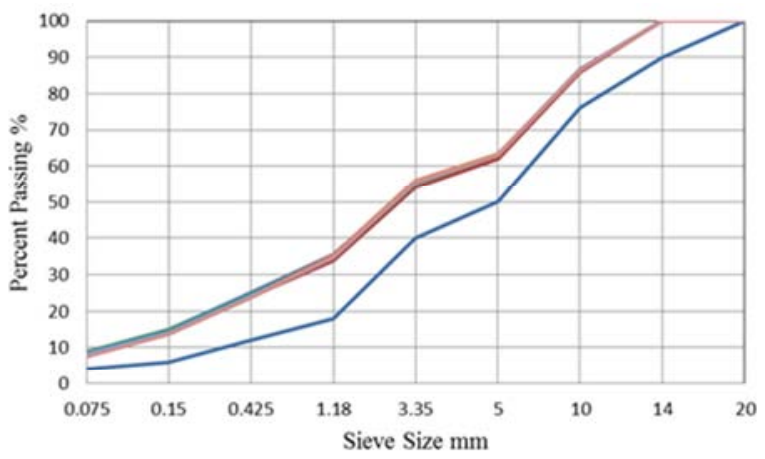

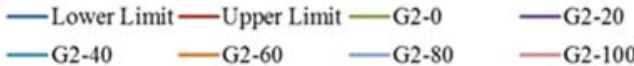

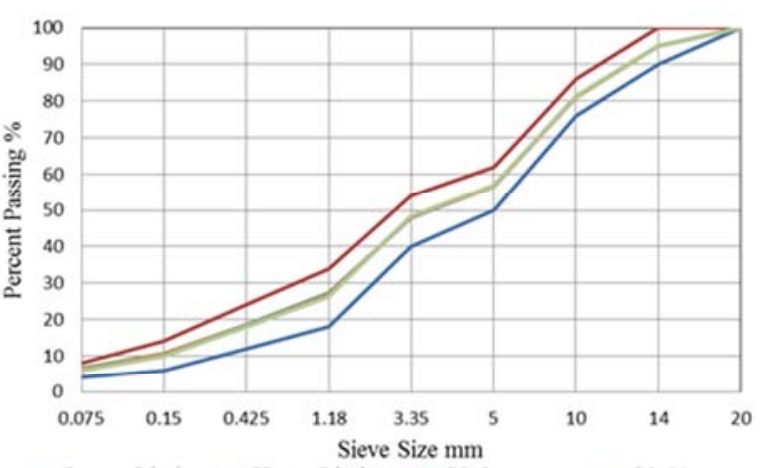

—Lower Limit —Upper Limit -G3-0 -G3-20

$-\mathrm{G} 3-40 \quad-\mathrm{G} 3-60 \quad-\mathrm{G} 3-80 \quad-\mathrm{G} 3-100$

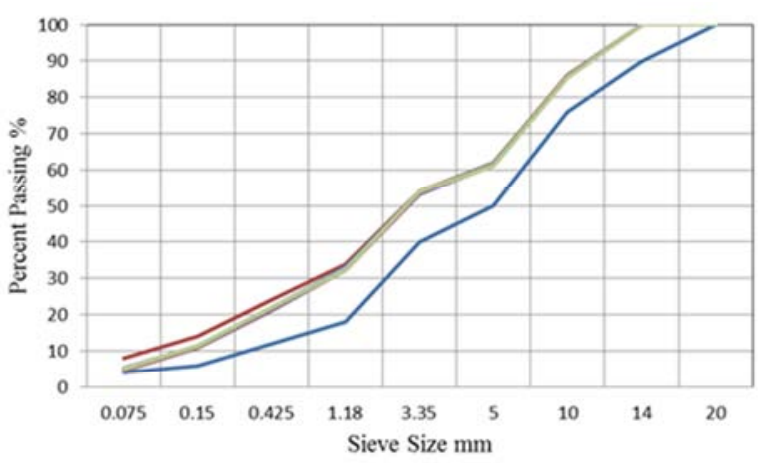

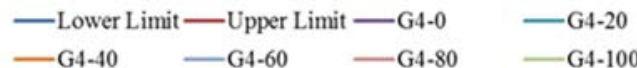

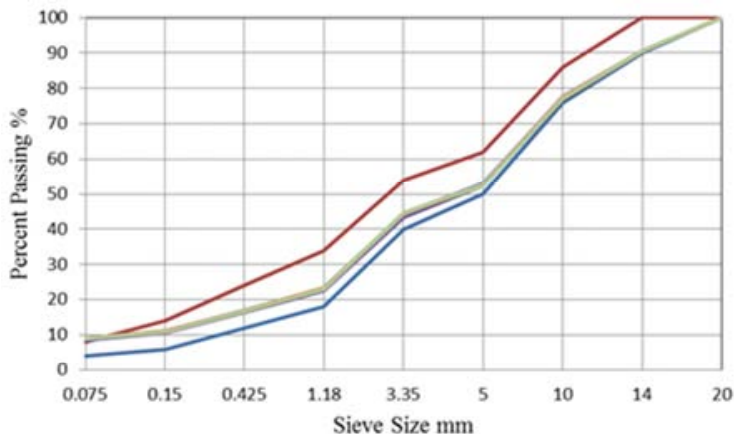

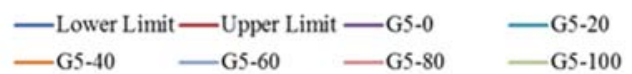

Figure 5. Passing Percentage after 20 Blows of Varies Gradation and RCA Proportions.

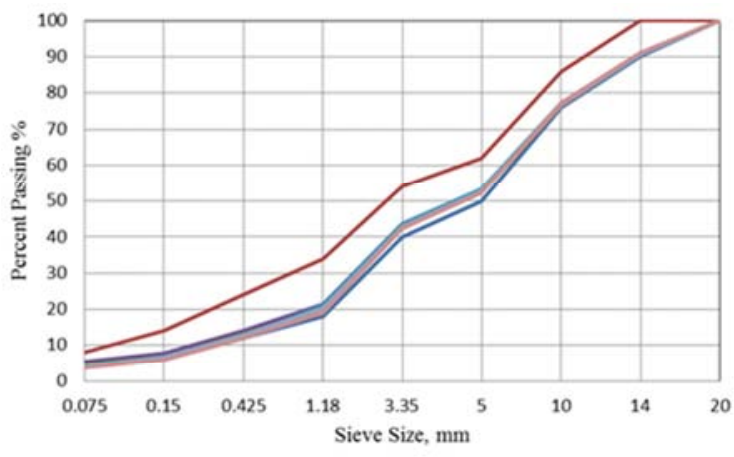

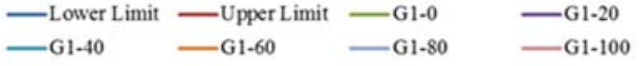

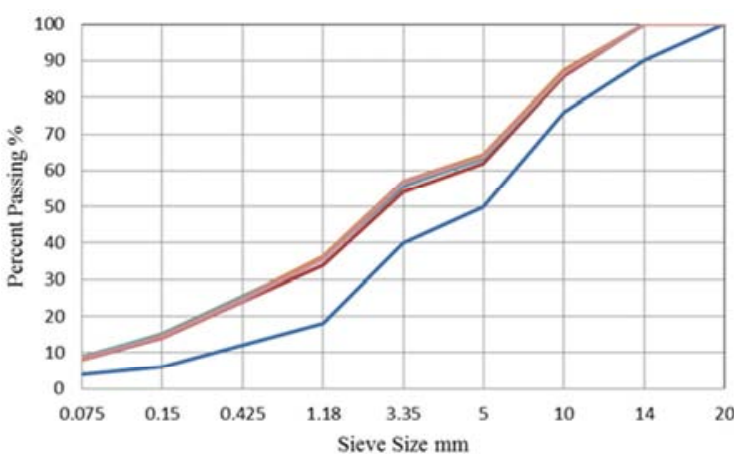

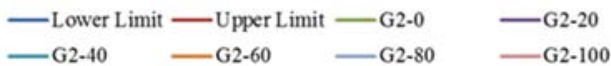



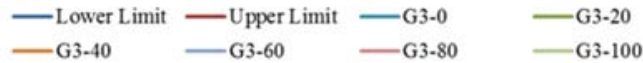



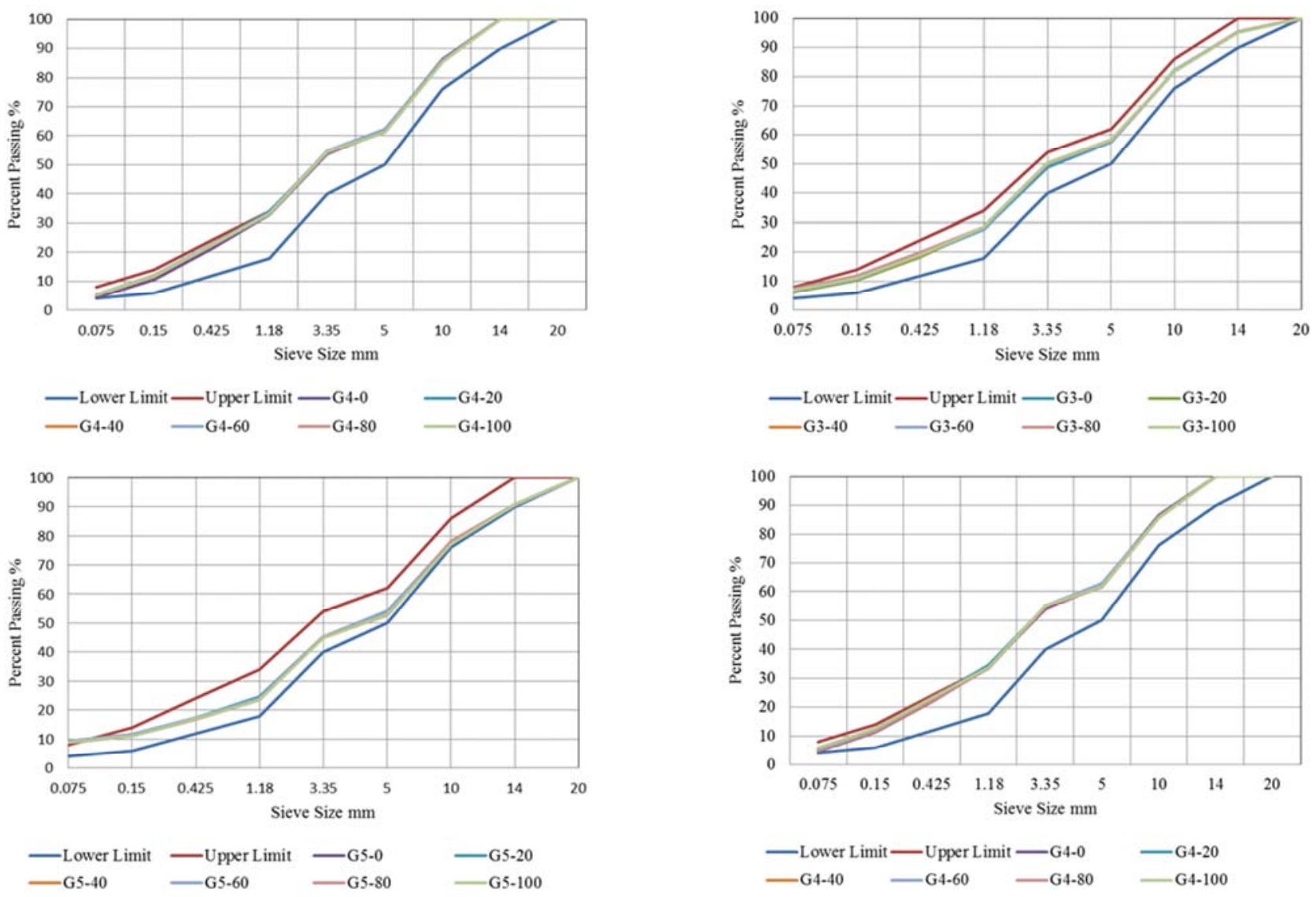

Figure 6. Passing Percentage after 40 Blows of Varies Gradation and RCA Proportions.


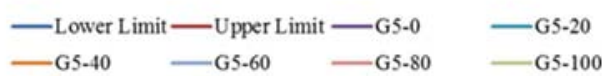

Figure 7. Passing Percentage after 60 Blows of Varies Gradation and RCA Proportions.



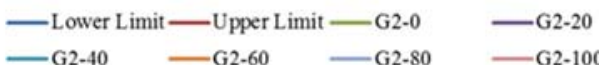

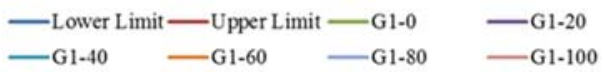






Lower Limit - Upper Limit $-\mathrm{G} 2-0-\mathrm{G} 2-20$
$-\mathrm{G} 2-40-\mathrm{G} 2-60-\mathrm{G} 2-100$

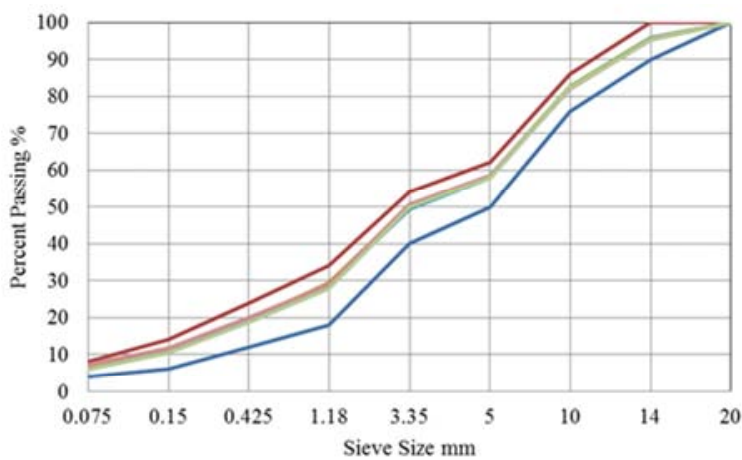

- Lower Limit -Upper Limit -G3-0 - G3-20

$-\mathrm{G} 3-40-\mathrm{G} 3-60-\mathrm{G} 3-80-\mathrm{G} 3-100$

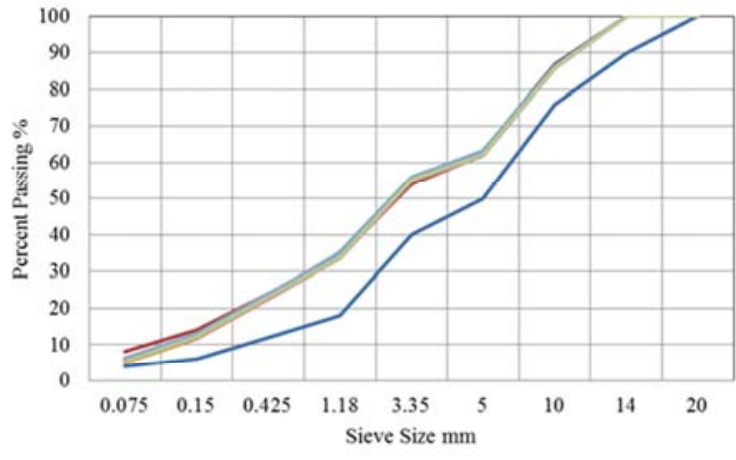

- Lower Limit —Upper Limit - G4-0 -

$-\mathrm{G} 4-40-\mathrm{G} 4-60-\mathrm{G} 4-80-\mathrm{G} 4-100$



- Lower Limit - Upper Limit - G5.0 - G5-20

Figure 8. Passing Percentage after 80 Blows of Varies Gradation and RCA Proportions.
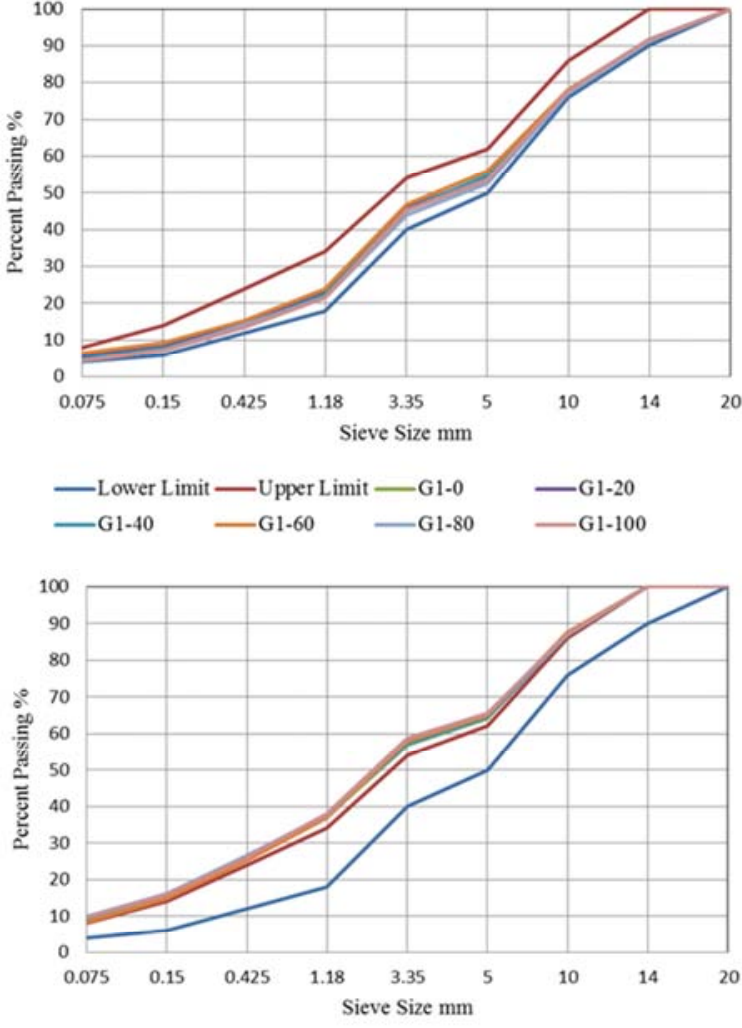

- Lower Limit -Upper Limit - G2-0 - $-\mathrm{G} 2-20$

$-\mathrm{G} 2-40-\mathrm{G} 2-60-\mathrm{G} 2-80-\mathrm{G} 2-100$

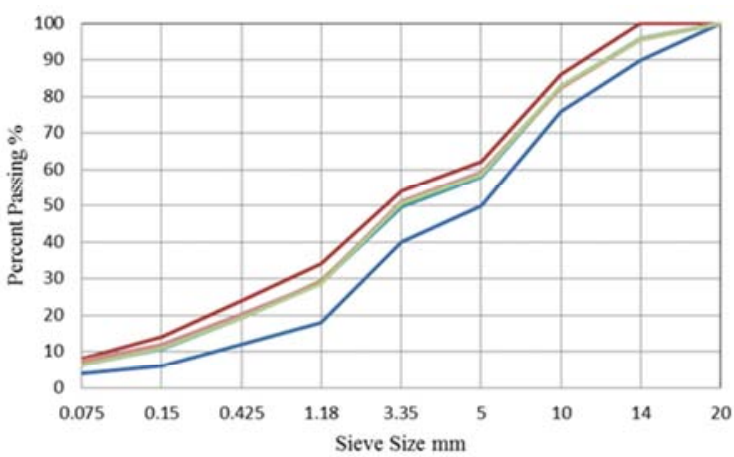

- Lower Limit - Upper Limit - G3-0 -G3-20

$-\mathrm{G} 3-40-\mathrm{G} 3-60-\mathrm{G} 3-80-\mathrm{G} 3-100$

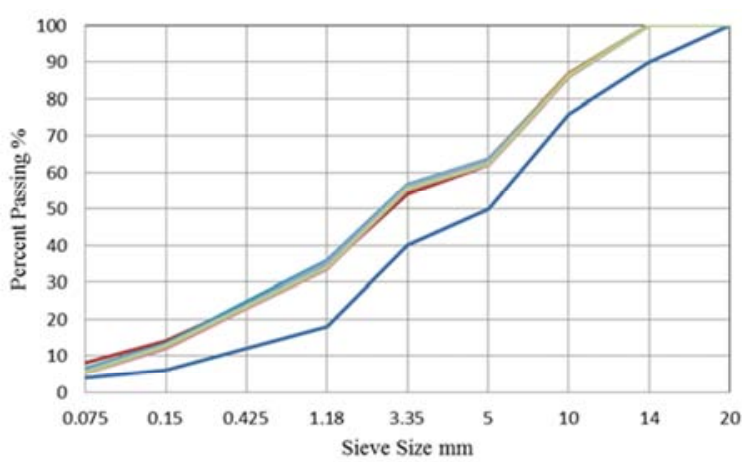

- Lower Limit -Upper Limit - G4-0 - G4-20

$-\mathrm{G} 4-40-\mathrm{G} 4-60-\mathrm{G} 4-80-\mathrm{G} 4-100$ 


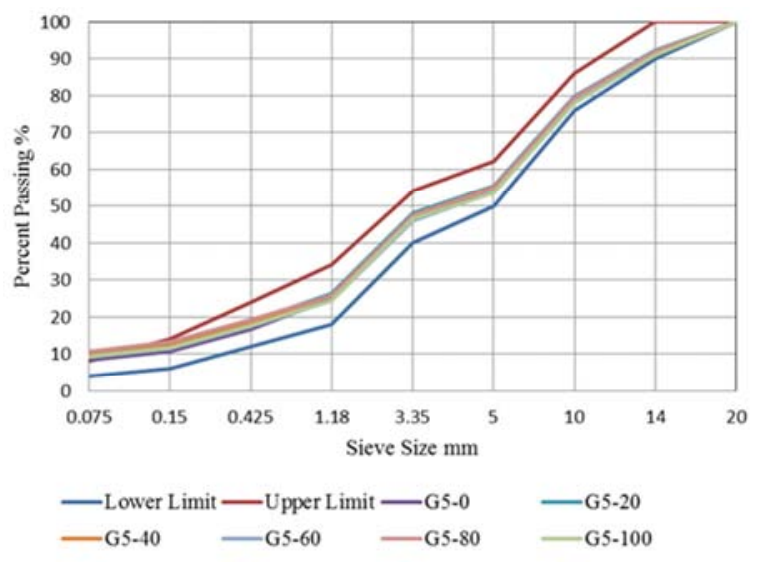

Figure 9. Passing Percentage after 100 Blows of Varies Gradation and RCA Proportions.

\subsection{Change in Passing Percentages for Sieve Sizes of 3.35 and $1.18 \mathrm{~mm}$}

Since the RCA used in this study had a passing sieve size of $5 \mathrm{~mm}$ and retained sieve size of $1.18 \mathrm{~mm}$, thus the focusing was on sieve sizes of $3.35 \mathrm{~mm}$ and $1.18 \mathrm{~mm}$ to $3.35 \mathrm{~mm}(\mathrm{G} 1)$

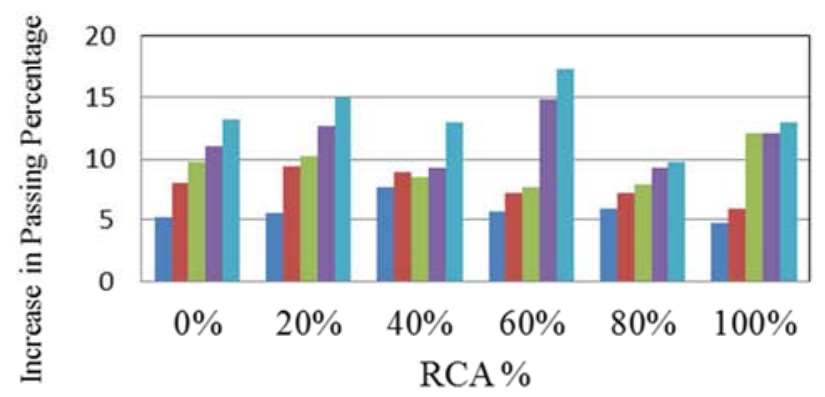

$3.35 \mathrm{~mm}(\mathrm{G} 3)$

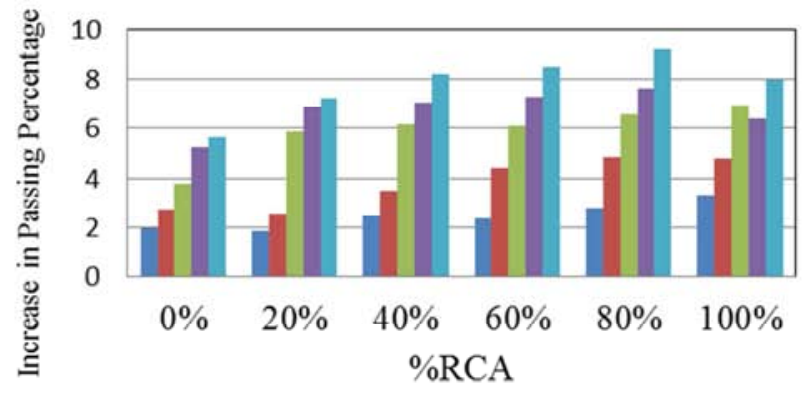

$3.35 \mathrm{~mm}(\mathrm{G} 5)$



better understand the effects of aggregate gradation and number of blows on the RCA degradation values. Figure 10 shows the change in passing percentage for a sieve size of $3.35 \mathrm{~mm}$ for all gradations and each number of blows. Figure 11 shows the change in passing percentage for a sieve size of $1.18 \mathrm{~mm}$ for all gradations and each number of blows. It can be observed from Figures 10 and 11 that RCA percentage did not affect the change in passing percentage, whereas aggregate gradation and number of blows did.

In order to better understand the effect of aggregate gradation on the degradation of RCA, Figures 10 and 11 were constructed for sieve sizes of 3.35 and 1.18 , respectively. From Figures 10 and $11 \mathrm{G} 2$ was the best gradation, followed by G3 and G4. G1 and G5 were the worst gradations. Such findings arose as $\mathrm{G} 2$ represents the dense-gradation. G2 and G4 were better than G1 and G5, because G2 and G4 contained more fine aggregate, and G1 and G5 contained more coarse aggregate. The fine aggregate protects the coarse aggregate from degradation. In addition, G2, G3 and G4 were more dense than G1 and G5. This is because G2, G3 and G4 were closer to the maximum density line on the 0.45 power gradation chart.
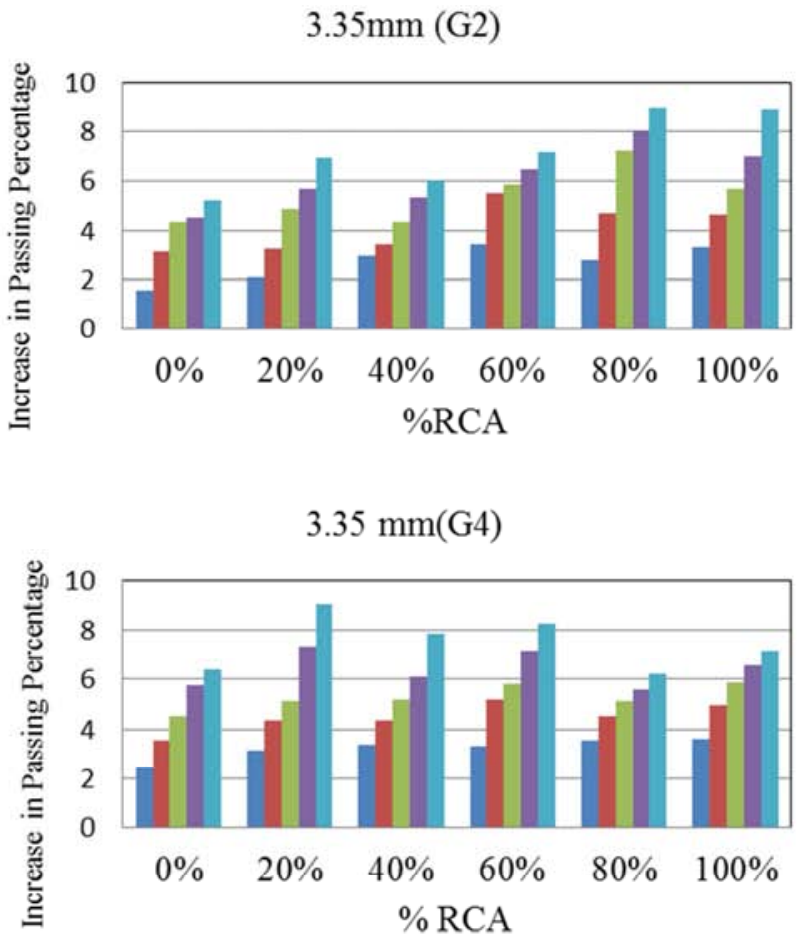

Figure 10. Change in Passing Percentages for Aggregate Retained Sieve size of $3.35 \mathrm{~mm}$. 
$1.18 \mathrm{~mm}(\mathrm{G} 1)$

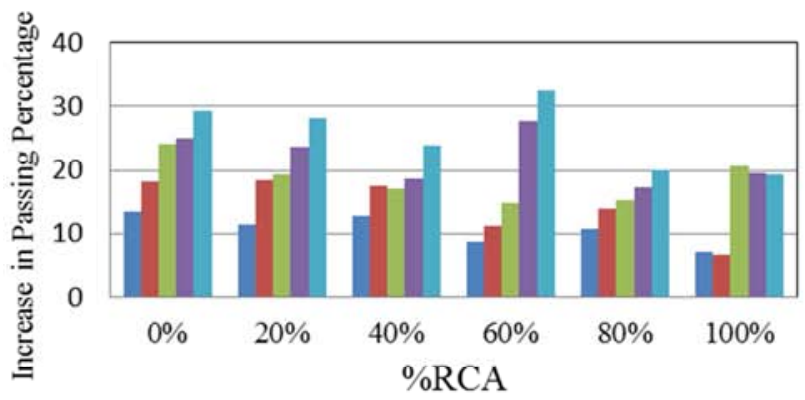

$1.18 \mathrm{~mm}(\mathrm{G} 3)$



$1.18 \mathrm{~mm}(\mathrm{G} 5)$

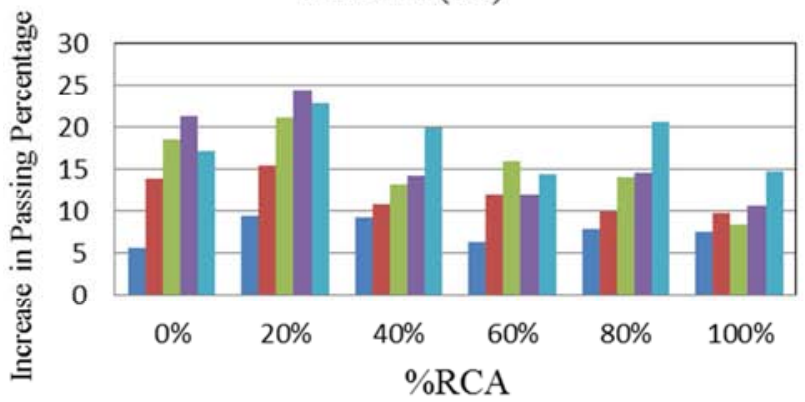

$1.18 \mathrm{~mm}(\mathrm{G} 2)$

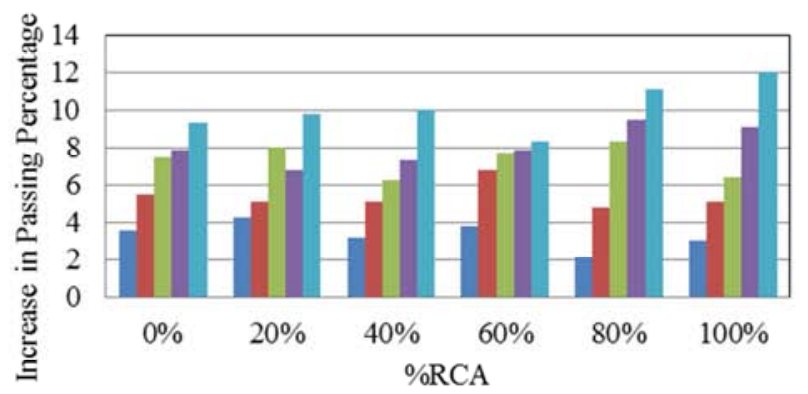

$1.18 \mathrm{~mm}(\mathrm{G} 4)$

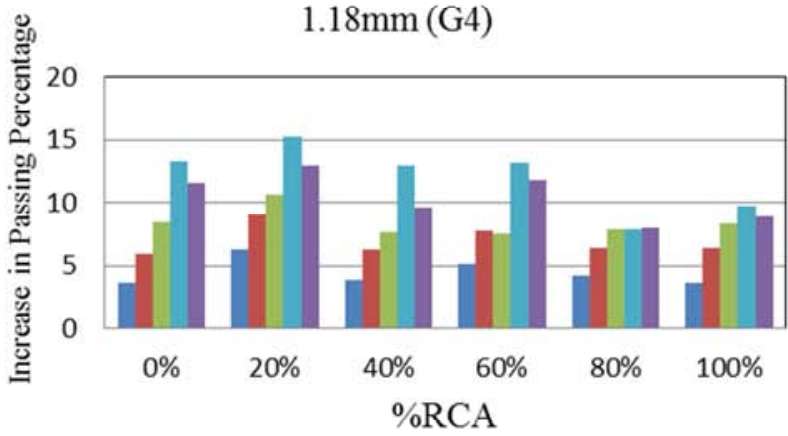

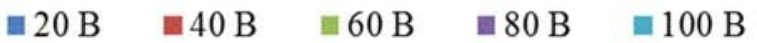

\subsection{Average Change in Passing Percentages for Aggregate Retained Sieve Size of 1.18, 3.35, 5, 10 And $14 \mathrm{~mm}$}

In order to evaluate the aggregate gradation and effect of number blows, the average of change in passing percentage is calculated for RCA proportions for each gradation. Then, the average of change in passing percentage is calculated for number of blows proportions for each gradation. Table 4 shows the calculated the average of change in passing percentage for aggregate retained sieve size of $1.18,3.35,5$, 10 and $14 \mathrm{~mm}$.

Table 4. Average Change in Passing Percentage.

\begin{tabular}{|c|c|c|c|c|c|c|}
\hline \multirow{2}{*}{ Gradation } & \multicolumn{5}{|c|}{ Number of Blows } & \multirow{2}{*}{ Average } \\
\hline & $20 \mathrm{~B}$ & $40 \mathrm{~B}$ & $60 \mathrm{~B}$ & $80 \mathrm{~B}$ & $100 \mathrm{~B}$ & \\
\hline \multicolumn{7}{|c|}{ Sieve Size of $1.18 \mathrm{~mm}$} \\
\hline G1 & 10.73 & 14.38 & 18.57 & 21.98 & 25.52 & 18.23 \\
\hline G2 & 3.33 & 5.42 & 7.39 & 8.10 & 10.10 & 6.87 \\
\hline G3 & 2.74 & 4.87 & 8.77 & 10.26 & 11.38 & 7.60 \\
\hline G4 & 4.46 & 6.98 & 8.42 & 10.48 & 12.02 & 8.47 \\
\hline G5 & 7.65 & 11.96 & 15.21 & 16.22 & 18.28 & 13.86 \\
\hline G1 & 5.80 & 7.78 & 9.36 & 11.54 & 13.51 & 9.60 \\
\hline G2 & 2.68 & 4.12 & 5.40 & 6.18 & 7.23 & 5.12 \\
\hline G3 & 2.46 & 3.79 & 5.92 & 6.76 & 7.81 & 5.35 \\
\hline G4 & 3.22 & 4.48 & 5.28 & 6.43 & 7.50 & 5.38 \\
\hline G5 & 4.32 & 6.21 & 8.29 & 8.71 & 10.61 & 7.63 \\
\hline
\end{tabular}




\begin{tabular}{|c|c|c|c|c|c|c|}
\hline \multirow{2}{*}{ Gradation } & \multicolumn{5}{|c|}{ Number of Blows } & \multirow{2}{*}{ Average } \\
\hline & $20 \mathrm{~B}$ & $40 \mathrm{~B}$ & $60 \mathrm{~B}$ & $80 \mathrm{~B}$ & $100 \mathrm{~B}$ & \\
\hline \multicolumn{7}{|c|}{ Sieve Size of $5.00 \mathrm{~mm}$} \\
\hline G1 & 3.96 & 5.14 & 5.41 & 6.74 & 8.23 & 5.90 \\
\hline G2 & 1.90 & 2.81 & 3.59 & 4.03 & 4.67 & 3.40 \\
\hline G3 & 1.41 & 2.29 & 3.73 & 4.14 & 4.82 & 3.28 \\
\hline G4 & 1.81 & 2.51 & 3.10 & 3.79 & 4.37 & 3.12 \\
\hline G5 & 1.36 & 2.49 & 3.79 & 3.60 & 4.82 & 3.21 \\
\hline \multicolumn{7}{|c|}{ Sieve Size of $10.00 \mathrm{~mm}$} \\
\hline G1 & 0.48 & 1.21 & 1.58 & 2.14 & 2.40 & 1.56 \\
\hline G2 & 0.73 & 1.01 & 1.19 & 1.30 & 1.46 & 1.14 \\
\hline G3 & 0.22 & 0.61 & 1.10 & 1.59 & 2.00 & 1.10 \\
\hline G4 & 0.27 & 0.46 & 0.62 & 0.85 & 1.13 & 0.67 \\
\hline G5 & 0.54 & 0.87 & 1.19 & 1.54 & 2.24 & 1.28 \\
\hline \multicolumn{7}{|c|}{ Sieve Size of $14.00 \mathrm{~mm}$} \\
\hline G1 & 0.70 & 0.88 & 1.24 & 1.53 & 1.74 & 1.22 \\
\hline G2 & 0.00 & 0.00 & 0.00 & 0.00 & 0.00 & 0.00 \\
\hline G3 & 0.05 & 0.16 & 0.31 & 0.56 & 0.72 & 0.36 \\
\hline G4 & 0.00 & 0.00 & 0.00 & 0.00 & 0.00 & 0.00 \\
\hline G5 & 0.02 & 0.14 & 0.29 & 0.57 & 0.99 & 0.40 \\
\hline
\end{tabular}
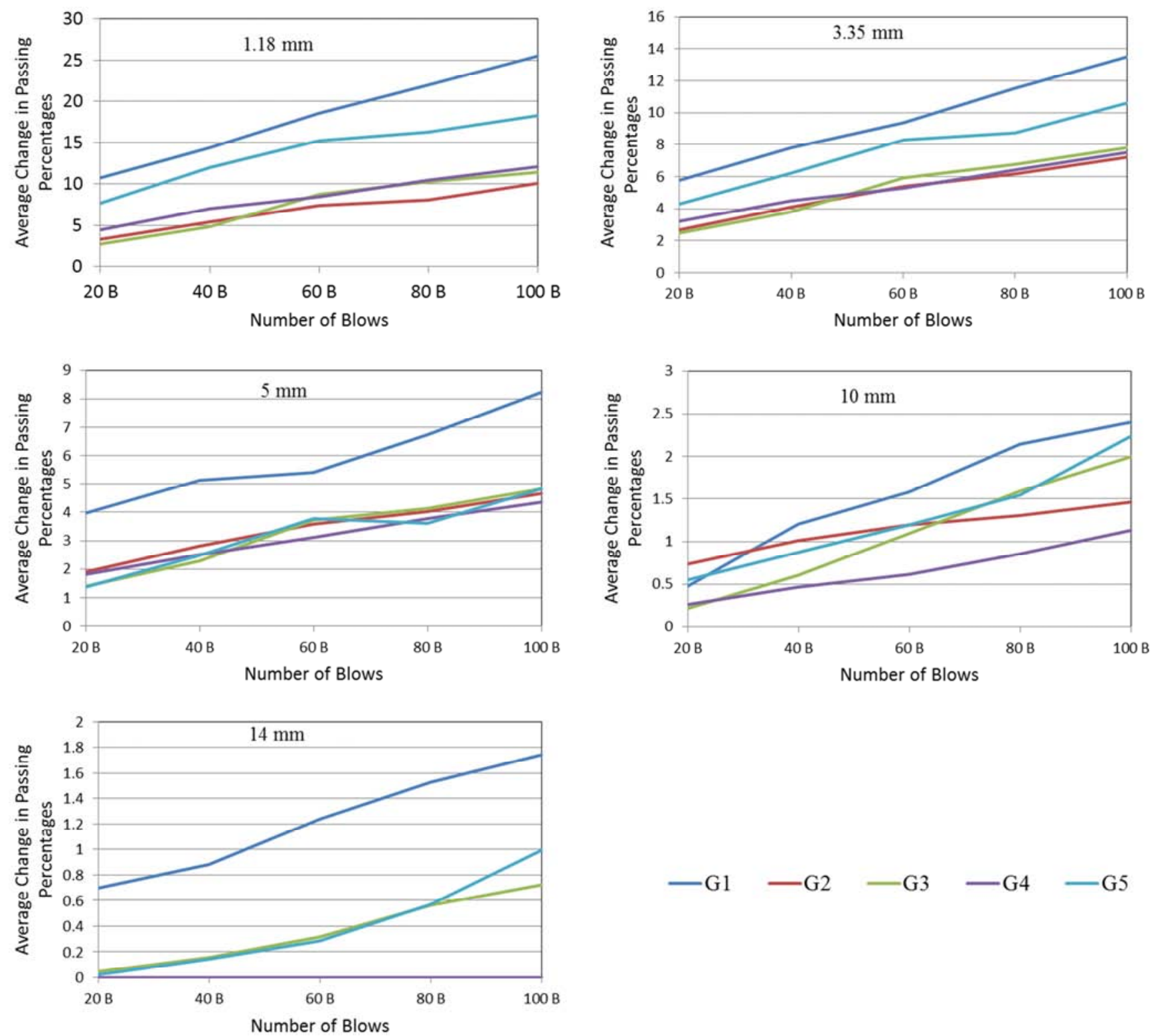

Figure 12. Average Change in Passing Percentages for each number of Blows. 
Figure 12 shows the average of change in passing percentages increases with increasing number of blow for all fractions and gradations. The gradation G1 is the worst gradation.

It can be noted from Table 4 the best gradation are G2, G3, G4, G5 and G1, respectively. That is because of the average change in passing percentages for aggregate retained sieve size of $1.18 \mathrm{~mm}$ are $6.87,7.60,8.47,13.86$ and 18.23 for gradations G2, G3, G4, G5 and G1, respectively. In addition, the average change in passing percentages for aggregate retained sieve size of $3.35 \mathrm{~mm}$ is $5.12,5.35,5.38,7.63$ and 9.6023 for gradations G2, G3, G4, G5 and G1, respectively.

The same conclusion can be noted for aggregate retained sieve size of 5, 10 and $14 \mathrm{~mm}$. Such findings arose as G2 represents the dense-gradation.. In addition, G2, G3 and G4 were more dense than G1 and G5. This is because G2, G3 and G4 were closer to the maximum density line on the 0.45 power gradation chart.

Figure 13 shows the average change in passing percentages is increase with decreasing aggregate particle size for all gradations. In addition the best gradation is G2, G3, G4, G5 and G1, respectively.

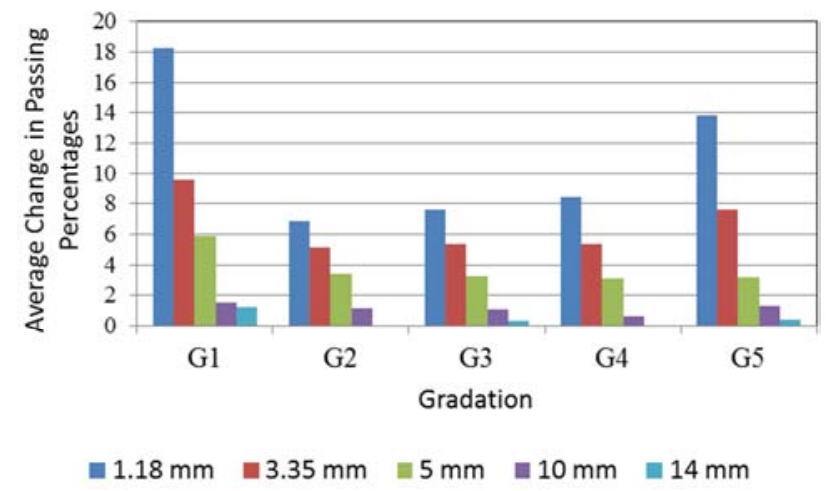

Figure 13. Average Change in Passing Percentages for each Gradation.

\section{Two-way Analysis of Variance (ANOVA)}

In order to evaluate the effect of RCA percentage and aggregate gradation on aggregate degradation, three properties were studied. These included the change in passing percentage for a sieve size of $3.35 \mathrm{~mm}$, change in passing percentage for a sieve size of $1.18 \mathrm{~mm}$ and the average change in passing percentage for each gradation.

The results for change in passing percentage for a sieve size of $3.35 \mathrm{~mm}$ were arranged with the gradation in columns and RCA content in rows. The ANOVA was performed with a significance level of 0.05 . The data are presented in Table 5. The decision rule was to reject the first null hypothesis (aggregate gradation did not have a significant effect on change in passing percentage for a sieve size of $3.35 \mathrm{~mm}$ ) because the calculated F-value of 18.7 exceeded the critical F-value of 2.45 , and the $\mathrm{p}$ value was $6 \mathrm{E}-12(<0.05)$. The decision rule was to accept the second null hypothesis (RCA content did not have a significant effect on the change in passing percentages for a sieve size of $3.35 \mathrm{~mm}$ ) because the calculated F-value of 0.8913 was smaller than the critical F-value of 2.28 , and the $\mathrm{p}$ value was $0.489(>0.05)$. The decision rule was to accept the third null hypothesis (the interaction between RCA percentage and aggregate gradation showed no significant effect on the change in passing percentage for a sieve size of $3.35 \mathrm{~mm}$ ) because the calculated F-value of 0.55 was smaller than the critical F-value of 1.66 , and the $\mathrm{p}$ value was $0.937(>0.05)$.

It can be concluded that aggregate gradation had a significant effect on the change in passing percentage for a sieve size of $3.35 \mathrm{~mm}$. On the other hand, RCA content showed no effect.

Table 5. Effect of Gradation and RCA Percentage in Change Passing Percentage for Sieve Size of $3.35 \mathrm{~mm}$.

\begin{tabular}{llllll}
\hline Source of Variation & SS & df & MS & F & P-value \\
\hline RCA \% & 27.29832 & 5 & 5.459664 & 0.891317 & 0.489291 \\
Gradation & 458.4734 & 4 & 114.6183 & 18.71201 & $5.63 \mathrm{E}-12$ \\
Interaction & 67.54199 & 20 & 3.377099 & 0.551328 & 0.937409 \\
Within & 735.0466 & 120 & 6.125388 & & 2.447237 \\
Total & 1288.36 & 149 & & & 1.65868 \\
\hline
\end{tabular}

The same procedure was repeated for the change in passing percentage for a sieve size of $1.18 \mathrm{~mm}$ and for each gradation. Table 6.

Table 6. Effect of Gradation and RCA Percentage in Change Passing Percentage for Sieve Size of $1.18 \mathrm{~mm}$.

\begin{tabular}{llllll}
\hline Source of Variation & SS & df & MS & F & P-value \\
\hline RCA \% & 244.8651 & 5 & 48.97303 & 2.476655 & 0.035752 \\
Gradation & 2865.678 & 4 & 716.4195 & 36.23063 & $7.82 \mathrm{E}-20$ \\
Interaction & 232.9945 & 20 & 11.64973 & 0.589148 & 0.91385 \\
Within & 2372.863 & 120 & 19.77386 & & 2.447237 \\
Total & 5716.401 & 149 & & & \\
\hline
\end{tabular}

For change in passing percentage for a sieve size of 1.18 $\mathrm{mm}$, aggregate gradation had a significant effect on change in passing percentage for a sieve size of $1.18 \mathrm{~mm}$, with a $\mathrm{p}$ value of $8 \mathrm{E}-02(<0.05)$. Whereas, RCA content had a weak significant effect because the calculated F-value of 2.47 was almost the same as the critical F-value of 2.28, compared 
with the calculated F-value of 36.2 and critical F-value of 2.44 for the effect of gradation.

Since RCA contents do not have significant effect on aggregate degradation and aggregate gradation has significant effect. Thus, the effect of aggregate gradation and number of blows were studied. The data are presented in Tables 7 and 8 . The effect was studied on the change in passing percentage for a sieve size of $3.35 \mathrm{~mm}$, change in passing percentage for a sieve size of $1.18 \mathrm{~mm}$ and average change in passing percentage for each gradation.

The results showed that both the number of blows and aggregate gradation had a significant effect on change in passing percentage for a sieve size of $3.35 \mathrm{~mm}$, change in passing percentage for a sieve size of $1.18 \mathrm{~mm}$ and average change in passing percentage for each gradation. The effect of number of blows was stronger than the effect of gradation.

Table 7. Effect of Gradation and Number of Blow in Change Passing Percentage for Sieve Size of $3.35 \mathrm{~mm}$.

\begin{tabular}{llllll}
\hline Source of Variation & SS & df & MS & F & P-value \\
\hline Gradation & 458.4734 & 4 & 114.6183 & 68.08986 & $1.78 \mathrm{E}-30$ \\
Number of Blow & 584.3069 & 4 & 146.0767 & 86.77794 & $3.99 \mathrm{E}-35$ \\
Interaction & 35.16253 & 16 & 2.197658 & 1.305535 & 0.203947 \\
Within & 210.4174 & 125 & 1.683339 & & 2.444174 \\
Total & 1288.36 & 149 & & & 1.725034 \\
\hline
\end{tabular}

Table 8. Effect of Gradation and Number of Blow in Change Passing Percentage for Sieve Size of $1.18 \mathrm{~mm}$.

\begin{tabular}{llllll}
\hline Source of Variation & SS & df & MS & F & P-value \\
\hline Gradation & 2865.678 & 4 & 716.4195 & 98.24271 & $1.25 \mathrm{E}-37$ \\
Number of Blow & 1757.525 & 4 & 439.3813 & 60.25243 & $2.91 \mathrm{E}-28$ \\
Interaction & 181.6548 & 16 & 11.35342 & 1.556897 & 0.090518 \\
Within & 911.5428 & 125 & 7.292342 & & 2.444174 \\
Total & 5716.401 & 149 & & & 1.725034 \\
\hline
\end{tabular}

It can be concluded that the number of blows had a strong effect on aggregate degradation, and aggregate gradation had an effect on degradation. Conversely, RCA content did not have an effect on aggregate degradation. Thus, selecting the appropriate level of traffic and aggregate gradation for hot mix asphalt that contains RCA is important.

\section{Conclusion}

Conclusions were derived from the experiments in which crushed concrete was mixed with natural granite and evaluations of the degradation after compaction. The following was found:

1. The quality of RCA is reduced below the standards of conventional aggregates by mortar connected to the surface of the RCA.

2. In samples that have the same level of compaction, aggregate degradation is most influenced by aggregate gradation. Dense aggregate gradation results in reduced degradation. Finer aggregate also protects coarse aggregate against degradation.

3. As the degradation increases when the number of blows exceeds 50, RCA is appropriate for surfaces exposed to low- and medium-volume traffic.

4. The different percentages of RCA do not influence aggregate degradation. This indicates that RCA can be used in the mixes if adequate fraction and gradation are selected and applied to suitable traffic volume.

\section{References}

[1] Friend of the earth.: 'Recycling why it's important and how to do it, Website: www.foe.co.uk (2008).

[2] Mahony, M. M.: Recycling of materials in civil engineering,
Phd Thesis, University of Oxford (1990).

[3] Pourtahmasb, M. S. and Karim, M. R.: Utilization of recycled concrete aggregates in stone mastic asphalt mixtures. Hindawi Publishing Corporation Advances in Materials Science and Engineering (2014).

[4] Symonds A, Cowi PRC Bouwcentrum.: Construction and demolition waste management practices, and their economic impacts, Report to DGXI European Commission (1999).

[5] Pasandin, A. R. and Perez, A.: Overview of bituminous mixtures made with recycled concrete aggregates, vol. 74, pp.151-161. Construction and Building Materials (2014).

[6] Arabani, M. and Azarhoosh, A.: The effect of recycled concrete aggregate and steel slag on the dynamic properties of asphalt mixtures, vol. 35, pp.1-7. Construction and Building Materials (2012).

[7] Pasand, A. R. and Perez, I.: Mechanical properties of hot-mix asphalt made with recycled concrete aggregates coated with bitumen emulsion, vol 55, pp. 350-358. Construction and Building Materials (2014).

[8] Pasand, A. R. and Perez, I.: Laboratory evaluation of hot-mix asphalt containing construction and demolition waste, vol. 43, pp.497-505. Construction and Building Materials (2013)

[9] Pérez, I., Pasandin, A. and Medina, L.: Hot mix asphalt using C\&D waste as coarse aggregates, vol. 36, pp.840-846. Journal of Materials \& Design (2012).

[10] Farias, M. M., Sinisterrra, F. and Jemenez, M.: Influence of asphalt rubber on the crushing of recycled aggregates used in dense HMA, Proceedings of Asphalt Rubber. Munic hhttp://www. ra-founda tion. org/wpcontent/uploads/2013/02/044-PAP_049. Pdf, (2012 ).

[11] Bushal, S., Li, X. and Wen, H.: Evaluation of effects of recycled concrete aggregate on volumetric of hot-mix asphalt, vol. 2205, pp. 36-39. Journal of the Transportation Research Board (2011). 
[12] Shen, D. H. and Du, J. C.: Application of gray relational analysis to evaluate HMA with reclaimed building materials. vol. 17, p. 4. Journal of Materials in Civil Engineering (2005).

[13] Bhusal, S. and Wen, H.: Evaluating recycled concrete aggregate as hot mix asphalt aggregate. vol. 2 p, 1 Paper ID ACEM20120053, Advances in civil engineering material (2013).

[14] Wen, H. and Mclean, D.: Evaluation of recycled concrete as aggregate in new concrete pavements. Washington state department of transportation Lynn Peterson, Secretary. Research Project (2014).

[15] Lynn, T., James, R. Wu, P and Jared, D.: Effect of Aggregate Degradation on Volumetric Properties of Georgia's Hot-Mix , Journal of the Transportation Research Board, pp. 123-131. Washington D. C. (2007).

[16] Roberts, F. L., Kandhal, P. S., Brown, E. R.; Lee, D. and Kennedy, T. W.: Hot Mix Asphalt Materials, Mixture Design, and Construction. 2nd Ed. National Asphalt Pavement Association Research and Education Foundation, Lanham, Maryland (1996).

[17] Gatchalian, D.: Characterization of aggregate resistance to degradation in stone matrix asphalt mixtures, Master Thesis, University of Texas A\&M (2005).

[18] Airey, G. D. Hunter, A. E. and Collop, A. C.: 'The effect of asphalt mixture gradation and compaction energy on aggregate degradation, vol. 22, pp.972-980. Construction and Building Materials (2007).
[19] Vavrik, W. R., Fries, R. J. and Carpenter, S. H.: Effect of flat and elongated coarse aggregate on characteristics of gyratory compacted samples, University of Illinois Urbana- Champaign, vol. 99-1338 Department of Civil Engineering (1999).

[20] Aho, B. D., Vavrik, W. R. and Carpenter, S. H.: Effect of flat and elongated coarse aggregate on field compaction of hotmix asphalt, University of Illinois Urbana- Champaign, Department of Civil Engineering, Journal of the Transportation Research Board (2001).

[21] ASTM C131. Standard Test Method for Resistance to Degradation of Small- Size Coarse Aggregate by Abrasion and Impact in the Los Angeles Machine, Annual Book of American Society for Testing materials ASTM Standards (2003).

[22] ASTM C127. Standard Test Method for specific Gravity and absorption of coarse aggregate . Annual Book of American Society for testing materials ASTM Standards (2003).

[23] ASTM C128. Standard Test Method for specific Gravity and absorption of fine aggregate, Annual Book of American Society for testing materials ASTM Standards (2003).

[24] ASTM D3398. Standard Test Method for index of aggregate particle shape and texture, Annual Book of American Society for Testing materials ASTM Standards (2003). 